\title{
AKTUALISASI INTERFERENSI BAHASA DAERAH DALAM BERTUTUR KATA PADA PEMBELAJARAN BAHASA INDONESIA DI SEKOLAH
}

\author{
Dwi Susilowati \\ SMK Negeri 2 Sukoharjo, Jawa Tengah \\ Email:dwiwakimin@gmail.com.id
}

\begin{abstract}
Abstrak : Bahasa Indonesia diadopsi dari Bahasa Melayu. Bahasa Indonesia dianggap lahir pada awal abad ke-20 bersamaan dengan lahirnya hari Kebangkitan Nasional. Latar belakang pemunculan interferensi bahasa dapat ditelusuri dari penutur dan bahasa yang dituturkannya. Weinreich (1970:64-65) mendeskripsikan beberapa faktor yang dapat dipandang sebagai latar belakang munculnya gejala interferensi, yaitu: (1) Kedwibahasaan para peserta tutur. (2) Kurangnya loyalitas pemakaian bahasa penerima. (3) Tidak cukupnya kosakata penerima dalam menghadapi kemajuan dan pembaruan.(4) Menghilangnya kata-kata yang jarang digunakan. (5) Kebutuhan akan sinonim.(6) Prestise bahasa sumber dan gaya bahasa. Interferensi merupakan salah satu faktor penyebab kesalahan berbahasa karena merusak sistem suatu bahasa. Interferensi merupakan kekeliruan yang disebabkan oleh adanya kecenderungan membiasakan pengucapan (ujaran) suatu bahasa terhadap bahasa lain. Cakupan pengucapannya adalah satuan bunyi, tata bahasa, dan kosakata. Secara umum, interferensi merupakan gejala bahasa yang timbul di dalam masyarakat bilingual dan atau multilingual. Kontak bahasa mengakibatkan terjadinya penyimpangan kaidah- kaidah bahasa, penyerapan dan penggunaan kosakata bahasa asing. Penyimpangan kaidah-kaidah bahasa dan penyerapan bahasa asing dikatakan sebagai interferensi. Penyimpangan kaidah bahasa berupa perubahan bunyi (fonologi), susunan kata berupa pola frase (morfologi) dan struktur kalimat (sintaksis). Penyerapan bahasa asing dapat berupa pengambilan kosakata asing dan penyesuaian ejaan bahasa asing ke dalam bahasa Indonesia. Penggunaan bahasa asing berupa leksikal yang belum atau tidak diindonesiakan. Berdasarkan uraian di atas dapat disimpulkan bahwa interferensi terjadi yang terjadi disebabkan oleh kekurangpengetahuan terhadap bahasa target. Sealin itu disebabkan oleh kedudukan lawan bicara dan faktor- faktor yang menyangkut pribadi seorang penutur yang tidak menguasai bahasa dalam masyarakat tutur. Walaupun peristiwa interferensi merupakan hal yang lazim dan wajar terjadi, akan tetapi cenderung bersifat merugikan dan merusak hubungan makna dalam berkomunikasi. Oleh karena itu, dalam berkomunikasi agar selalu menerapkan kaidah berbahasa agar tidak terjadi kesalahpahaman.
\end{abstract}

Kata Kunci: aktualisasi, interferensi, bahasa daerah, bahasa Indonesia

Abstract : Indonesian is adopted from Malay. Indonesian is considered to be born at the
beginning of the 20th century along with the birth of National Awakening day. The
background of the appearance of language interference can be searched from the speakers
and the language it speaks. Weinreich (1970: 64-65) describes several factors that can be
regarded as the background of the emergence of interference symptoms, namely: (1)
Biblical of the participants said. (2) Lack of loyalty in the use of recipient language. (3)
Inadequate vocabulary of the recipient in the face of progress and renewal. (4) 
Disappearance of rarely used words. (5) The need for synonyms. (6) Prestige of source language and language style. Interference is one factor causing language errors because it destroys the system of a language. Interference is an error caused by the tendency to accustom the pronunciation (speech) of a language to another language. Speech coverage is the unit of sound, grammar, and vocabulary. In general, interference is a symptom of language that arises in a bilingual and / or multilingual society. Language contacts result in the deviation of language rules, the absorption and use of foreign language vocabulary. The deviation of language rules and the absorption of foreign languages is said to be interference. The deviation of the language rules of sound changes (phonology), wording in the form of phrase patterns (morphology) and sentence structure (syntax). Absorption of foreign languages can take the form of foreign vocabulary and foreign language spelling adjustments into Indonesian. The use of foreign languages in the form of lexical not yet or not in Indonesia. Based on the above description it can be concluded that interference occurs that occurs due to lack of knowledge of the target language. Sealin is caused by the position of the other person and the factors that concern the person of a speaker who does not speak the language in the speech community. Although interference events are common and natural, but tend to be detrimental and detrimental to the relationship of meaning in communication. Therefore, in communicating to always apply the rules of language in order to avoid misunderstandings.

Keywords: actualization, interference, regional language, Indonesian language

\section{PENDAHULUAN}

Bahasa Indonesia dan bahasa daerah merupakan unsur budaya Indonesia. Bahasabahasa tersebut mendapat tempat tersendiri di dalam khasanah kebudayaan Indonesia yang perlu dilindungi dan dibina. Kederadaan dua bahasa itulah yang kemudian menimbulkan interferensi. Pendapat ini dikemukakan Suwito yang sejalan dengan apa yang dikatakan oleh Moeliono,(1988: 20),'Proses pemengaruhan antara bahasa Indonesia dengan bahasa daerah bersifat timbal balik". Dalam berbahasa dan berbudaya itu terkait dengan konteks untuk berkomunikasi. Konteks bahasa yang dimaksud mengarah pada koneks peraturan atau situasi yang dapat mencakup aspek identitas partisipan, waktu, dan tempat peristiwa komunikasi, topik pertuturan, dan tujuan pertuturan. Konteks kebahasaan ini mengisyaratkan bahwa setiap pemakai bahasa dalam mengadakan interaksi sosial atau komunikasi terpola oleh kebudayaan yang dimilikinya. Konteks kebudayaan merupakan konteks yang relatif umum dan berlaku dalam masyarakat bahasa (Levinson, 2000)

Terciptanya proses komunikasi dapat berupa komunikasi lisan maupun tertulis. Komunikasi bisa terjadi dengan menggunakan bahasa, baik lisan maupun tulis. Hal itu bertujuan hendak disampaikan kepada lawan bicara atau para pembaca. Penggunaan bahasa yang tercipta dalam komunikasi disesuaikan dengan kebutuhan dan keutuhan informasi agar mudah dicerna dan dipahami. Hal ini ditekankan pada bahasa tulis yang ada 
di lingkungan masyarakat, baik yang berupa buku, artikel, modul, karya terjemahan, dan lain-lain.

Latar belakang pemunculan interferensi bahasa dapat ditelusuri dari penutur dan bahasa yang dituturkannya. Weinreich (1970:64-65) mendeskripsikan beberapa faktor yang dapat dipandang sebagai latar belakang munculnya gejala interferensi, yaitu: (1) Kedwibahasaan para peserta tutur. (2) Kurangnya loyalitas pemakaian bahasa penerima. (3) Tidak cukupnya kosakata penerima dalam menghadapi kemajuan dan pembaruan.(4) Menghilangnya kata-kata yang jarang digunakan. (5) Kebutuhan akan sinonim.(6) Prestise bahasa sumber dan gaya bahasa.

Di samping pendapat Weinreich di atas, Ohoiwutun (2007:72) mengatakan bahwa gejala interferensi dapat dilihat dalam tiga dimensi kejadian. Pertama, dimensi tingkah laku berbahasa dari individu-individu di tengah masyarakat. Kedua, dari dimensi sistem bahasa dari kedua bahasa atau lebih yang berbaur. Ketiga, dimensi pembelajaran bahasa.

Dimensi pertama, menurut Ohuiwutun (2007:72-73), "Dari dimensi tingkah laku penutur dengan mudah dapat disimak dari berbagai praktik campur kode yang dilakukan penutur yang bersangkutan." Dimensi pertama ini terjadi karena murni rancangan atau model buatan penutur itu sendiri. Hal ini dapat dilakukan dengan cara mentransfer satu atau lebih komponen dari bahasa yang satu untuk dirakit dan diramu dalam konteks bahasa yang lain.

Dimensi kedua, menurut Ohuiwutun (2007:73), "Dari dimensi sistem bahasa dikenal sebagai interferensi sistemik, yaitu pungutan bahasa." Interferensi leksikal sistemik terjadi karena penyesuaian ejaan dari bahasa yang satu dalam konteks bahasa yang lain. Di dalam proses pungutan bahasa ini, interferensi leksikal sistemik dapat terjadi penggunaan leksikal bahasa asing dan yang sudah disistemikkan tetapi masih menggunakan bahasa asing karena ketidaktahuan pengguna bahasa. Bahkan, dapat terjadi proses pungutan bahasa yang mengabaikan interferensi leksikal sistemik dengan cara penggunaan leksikal serapan langsung dan leksikal bahasa asing yang belum diserap ke dalam bahasa Indonesia. Interferensi leksikal, penggunaan leksikal yang sudah disistemikkan tetapi masih menggunakan bahasa asing, leksikal serapan langsung, dan leksikal bahasa asing yang sudah diserap ke dalam bahasa Indonesia menjadi fokus penelitian ini.

Dimensi ketiga dalam gejala interferensi yang dikemukakan oleh Ohoiwutun (2007:74-75) biasanya dinamai interferensi karena pendidikan. Di dalam hal ini dikenal transfer positif dan transfer negatif. Transfer positif terjadi apabila pembelajar menyesuaikan unsur-unsur yang mirip dan sama dari bahasa kedua atau asing dengan bahasa pertama dan bahasa asing sangat berlainan sehingga hampir tidak memiliki komponen yang semirip sehingga proses pembelajaran semakin rumit.

Berdasarkan pendapat di atas, latar belakang interferensi bahasa berkaitan erat dengan sikap bahasa. Menurut Bawa (1981:8) terdapat tiga ciri pokok perilaku atau sikap bahasa. Ketiga ciri pokok sikap bahasa itu adalah (i) language loyality, yaitu sikap loyalitas/kesetiaan terhadap bahasa; (ii) language pride, yaitu sikap kebanggaan terhadap bahasa; dan (iii) awareness of the norm, yaitu sikap sadar adanya norma bahasa. Jika 
wawasan terhadap ketiga ciri pokok atau sikap bahasa itu kurang sempurna dimiliki seseorang, berarti penutur bahasa itu bersikap kurang positif terhadap keberadaan bahasanya. Bahkan, menurut Sugono, dkk. (2006b:70), "Penggunaan unsur-unsur bahasa asing dalam wacana/kalimat bahasa Indonesia sangat berkaitan erat dengan masalah sikap bahasa. Sikap bahasa yang kurang positif, kurang bangga terhadap bahasa Indonesia, yang sebenarnya tidak perlu terjadi." Kecenderungan sikap bahasa seperti ini dapat dipandang sebagai latar belakang munculnya interferensi bahasa bahasa asing terhadap bahasa pertama.

\section{KAJIAN TEORI}

Interferensi pernah ditulis Aslinda (1994), tentang "Interferensi Bahasa Nias dengan Bahasa Minangkabu di Desa Tanjung Basung II". Penelitian ini bertujuan untuk mendapatkan deskripsi mengenai faktor-faktor apa yang menyebabkan timbulnya interferensi dan jenis serta bentuk interferensi yang ada dari bahasa Nias terhadap bahasa Minangkabau di Desa Tanjung Basung II. Erita (1997), tentang "Interferensi Bahasa Indonesia di Minangkabau dalam Penyebutan Nama-nama Kelurahan di Kota Padang: Penelitian ini yang bertujuan untuk mendeskripsikan bentuk-bentuk interferensi bahasa Indonesia di Minangkabau, dalam penyebutan nama-nama Kelurahan yang terdapat di Kota Padang oleh masyarakat penutur dari berbagai golongan. Damayanty (1997), menulis tentang "Interferensi Bahasa Minangkabau dalam Bahasa Indonesia Pada Surat Kabar Singgalang dan Haluan”. Penelitian ini membahas bentuk dan fungsi interferensi bahasa Minangkabau ke dalam bahasa Indonesia pada surat kabar Singgalang dan Haluan. Syahdiza (2013), menulis tentang "Interferensi Leksikal Bahasa Inggris dalam Acara „Eight-Eleven Show" di Metro TV”.

Tulisan- tulisan tersebut bertujuan untuk mendeskripsikan interferensi leksikal bahasa Inggris terhadap penggunaan bahasa Indonesia yang digunakan para pengisi acara di program ,eight-eleven " show Metro TV.

Interferensi merupakan salah satu faktor penyebab kesalahan berbahasa dan dipandang sebagai pengacu karena merusak sistem suatu bahasa. Menurut para ahli, istilah interferensi pertama kali digunakan oleh Wenreich (Abdul Chaer Leoni Agustina 1953: 120) untuk menyebut adanya perubahan sistem suatu bahasa sehubungan adanya persentuhan bahasa dengan unsur bahasa lain yang dilakukan olehpenutur yang bilingual.

Interferensi merupakan kekeliruan yang disebabkan oleh adanya kecenderungan membiasakan pengucapan (ujaran) suatu bahasa terhadap bahasa lain mencakup pengucapan satuan bunyi, tata bahasa, dan kosakata Alwasilah (1985: 131).

Ohoiwutun (2007:72) mengatakan bila dua atau lebih bahasa bertemu karena digunakan oleh penutur dari komunitas yang sama, maka akan terjadi bahwa komponenkomponen tertentu dapat tertransfer dari bahasa yang satu, yakni bahasa sumber (source or donor language) ke bahasa lain yakni bahasa penerima (recipient language). Akibatnya 
terjadi pungutan bahasa atau 'interference' sebagaimana diistilahkan oleh Weinreich (1970).

Selanjutnya, Ohoiwutun (2007:72) mengutip pendapat Mackey (1972) membedakan antara campur kode dengan interferensi bahasa. Campur kode dikatakan sebagai interferensi sedangkan interferensi disebut sebagai integrasi. Begitu pula halnya dengan Mustakim (1994:13), yang mengutip pendapat Mackey (1972) mengungkapkan bahwa masalah interferensi adalah nisbi, tetapi kenisbiannya itu dapat diukur.

Berdasarkan beberapa pendapat di atas disimpulkan bahwa interferensi merupakan gejala yang timbul di dalam masyarakat bilingual dan atau multilingual karena adanya kontak bahasa yang mengakibatkan terjadinya penyimpangan kaidah- kaidah bahasa, penyerapan dan penggunaan kosakata bahasa asing. Penyimpangan kaidah-kaidah bahasa dan penyerapan bahasa asing dapatlah dikatakan sebagai interferensi. Penyimpangan kaidah bahasa berupa perubahan bunyi (fonologi), susunan kata berupa pola frase (morfologi) dan struktur kalimat (sintaksis). Penyerapan bahasa asing dapat berupa pengambilan kosa kata asing dan penyesuaian ejaan bahasa asing ke dalam bahasa Indonesia. Penggunaan bahasa asing berupa leksikal yang belum atau tidak diindonesiakan.

\section{METODE}

Penelitian ini menggunakan penelitian studi pustaka, berupa mengadakan penelitian dengan cara mempelajari dan membaca literatur-literatur yang memiliki hubungan dengan permasalahan-permasalahan yang menjadi obyek dalam penelitian.

\section{PEMBAHASAN}

\section{Peran dan Variasi Bahasa}

Bahasa mengambil tiga fungsi yaitu fungsi komunikatif, ekspresif, dan deskriptif. Pertama, komunikatif berarti bahasa berfungsi sebagai sarana untuk berkomunikasi. Kedua, ekspresif yakni bahasa sebagai sarana yang memberikan kesaksian tentang kenyataan diri kita untuk disampaikan kepada orang lain. Ketiga, fungsi deskriptif yaitu bahasa mampu menghasilkan pengetahuan tentang sesuatu. Ketiga hal tersebut dapat diwujudkan dalam bentuk ujaran lisanmaupun rangkaian bahasa yang berbentuk tulisan.

Bahasa Indonesia harus diujarkan dalam bentuk yang baik dan benar. Baik artinya harus disesuaikan dengan situasi dan kondisi paetisipan yang diajak bicara. Benar artinya bahasa harus disampaikan sesuai dengan kaidah bahasa yang resmidan sesuai aturan. Kegiatan berbahasa tidak hanya berdasar pada bentuk-bentuk bahasanya saja melainkan juga harus memperhatikan aspek kesopanan dan prinsip kerja sama.Leech (1993) menjelaskan bahwa prinsip kerja sama dibutuhkan untuk mempermudah menjelaskan hubungan antara makna dan daya. Penjelasan yang demikian sangat memadai khususnya untuk memecahkan masalah yang timbul dalam semantik yang memakai pendekatan berdasarkan kebenaran (truth- based approach). Prinsip kerja sama tersebut tidak menjelaskan perilaku namun dalam sebuah pernyataan menjelaskan bahwa kesopanan membawa peran sangat penting. 
Secara bilingual tidak terlepas dari sebuah interferensi, secara makna praktiknya interferensi yaitu terjadinya kontak bahasa Ibu yang mempengaruhi bahasa kedua. Interferensi sering dialami oleh seseorang yang secara kebiasaan sudah menggunakan bahasa Daerah sebagai bahasa pengantarnya. Penyebab permasalahan masuknya bahasa Ibu ke dalam bahasa keduadiakibatkan berbagai faktor. Adanya heterogenitas latar belakang hidup, sumber daya manusia, atau pengetahuan.

Lingkungan merupakan tempat untuk memperoleh bahasa melalui tindak tutur menggunakan bahasa Ibu. Terkait dengan interferensi, di sana terjadi campur tangan. Masyarakat di daerah pebatasan akan menggunakan tiga bahasa karena secara geografis mereka menggunakan dua bahasa dan satu bahasa Indonesia.

Istilah interferensi berasal bahasa Inggris yang disebut interference 'gangguan'. Istilah interferensi digunakan pertama kali dalam sosiolinguistik oleh Weinreich (1970:1) yang mengatakan bahwa interferensi bahasa adalah suatu bentuk penyimpangan dalam penggunaan bahasa dari norma-norma yang ada sebagai akibat adanya kontak bahasa atau pengenalan lebih dari satu bahasa dan digunakan secara bergantian oleh penuturnya. Selanjutnya, Weinreich menekankan interferensi adalah pemindahan unsur-unsur bahasa ke dalam bahasa lain dan penyimpangan penggunaan kaidah dan norma- norma bahasa. Sebagaimana yang telah diungkapkan sebelumnya, bahwa akibat adanya masyarakat yang bilingual ataupun dwibahasawan seperti yang terjadi pada masyarakat Indonesia, muncullah suatu fenomena bahasa yang disebut dengan interferensi.

Lado (1957:217) mengatakan bahwa interferensi adalah kesulitan yang timbul dalam proses penguasaan bahasa kedua dalam hal bunyi, kata, atau konstruksi sebagai akibat perbedaan kebiasaan dengan bahasa pertama. Chaer (1999:66) menyatakan bahwa dalam peristiwa bahasa pada masyarakat bilingual atau multilingual yang disebabkan kontak bahasa, sering terjadi interferensi, yakni masuknya unsur-unsur bahasa lain ke dalam bahasa yang sedang digunakan sehingga terjadi penyimpangan kaidah dari bahasa yang digunakan. Selanjutnya, interferensi bisa terjadi mulai dari tataran fonologi, morfologi, sintaksis, sampai dengan ketataran wacana.

\section{Faktor Penyebab Interferensi}

Kedwibahasaan peserta tutur dapat menyebabkan terjadinya interferensi, baik yang berupa bahasa asing maupun bahasa daerah. Tipisnya kesetiaan pemakai bahasa penerima cenderungakan menimbulkan sikap yang kurang positif.

Pendapat lain dikemukakan Jendra (1991: 105;). Interferensi terjadi tiga unsur pokok, yaitu bahasa sumber atau bahasa donor, yaitu bahasa yang menyusup unsuunsurnya atau sistemnya ke dalam bahasa lain; bahasa penerima atau bahasa resepian, yaitu bahasa yang menerima atau bahasa yang disisipi oleh bahasa sumber; dan adanya unsur bahasa yang terserap (importasi) atau unsur serapan.

Ohoiwutun menganggap seluruh kata yang berasal dari bahasa lain merupakan interferensi. Interferensi bahasa yang sudah masuk ke dalam suatu bahasa penerima baik diserap langsung maupun melalui penyesuaian ejaan bahasa penerima merupakan integrasi. 
Perbedaan antara interferensi dengan integrasi sangatlah tipis. Perbedaannya yaitu kata yang sudah diserap ke dalam bahasa penerima disebut sebagai interferensi yang sudah berintegrasi.

Berdasarkan beberapa pendapat di atas dapatlah dikatakan bahwa interferensi merupakan gejala yang timbul di dalam masyarakat bilingual dan atau multilingual karena adanya kontak bahasa yang mengakibatkan terjadinya penyimpangan kaidah- kaidah bahasa, penyerapan dan penggunaan kosakata bahasa asing. Penyimpangan kaidah-kaidah bahasa dan penyerapan bahasa asing dapatlah dikatakan sebagai interferensi. Penyimpangan kaidah bahasa berupa perubahan bunyi (fonologi), susunan kata berupa pola frase (morfologi) dan struktur kalimat (sintaksis). Penyerapan bahasa asing dapat berupa pengambilan kosa kata asing dan penyesuaian ejaan bahasa asing ke dalam bahasa Indonesia. Penggunaan bahasa asing berupa leksikal yang belum atau tidak diindonesiakan.

\section{Tataran Interferensi Bahasa}

Chaer (1999:66) mengemukakan interferensi dapat terjadi dalam semua tataran bahasa, misalnya dalam tataran fonologi, morfologi, dan sintaksis. Ketiga tataran ini dalam bahasa Indonesia, khususnya dalam penulisan nama badan usaha, mengalami interferensi sebagai berikut:

1) Interferensi fonologi merupakan perubahan bunyi bahasa yang seharusnya diucapkan menurut bahasa Indonesia tetapi diucapkan menurut bahasa asing. Contohnya bunyi /c/ diucapkan $/ \mathrm{se} /$ atau $/ \mathrm{k} /$.

2) Interferensi morfologi merupakan interferensi yang terjadi dalam pembentukan kata, leksikal, dan frase. Pembentukan kata, contohnya, legalisasi, premanisme, pascasunami, dan ekspress. Pembentukan leksikal yaitu penggunaan kata asing, baik sudah ada padanannya maupun belum ada padanannya. Contohnya internet, florist, mouse, collection, dan fashion. Pembentukan frase sangat sering terjadi dalam penulisan nama badan usaha swasta. Interferensi ini, misalnya, dalam bahasa Indonesia menggunakan struktur DM (Diterangkan Menerangkan) sementara bahasa Inggris menggunakan struktur MD (Menerangkan Diterangkan). Contohnya, Annie Sui Beauty Salon, dan Farhan Florist.

3) Interferensi sintaksis jarang terjadi, khususnya dalam konteks penulisan nama badan usaha swasta. Interferensi sintaksis berupa klausa atau kalimat. Interfernsi ini kadangkadang terlihat pada papan nama badan usaha yang memromosikan nama usaha, keunggulan, jenis usaha, dan lain-lain. Contohnya, East and on time delivery.

Jendra (1991:108) membedakan tataran interferensi bahasa menjadi lima aspek kebahasaan. Kelima aspek kebahasaan dalam tataran interferensi bahasa itu adalah:

1) Interferensi pada bidang sistem tata bunyi (fonologi).

2) Interferensi pada tata bentukan kata (morfologi).

3) Interferensi pada tata kalimat (sintaksis).

4) Interferensi pada kosakata (leksikon).

5) Interferensi pada bidang tata makna (semantik). 
Secara khusus, menurut Jendra (1991:113) tataran interferensi bahasa pada bidang semantik masih dapat dibedakan lagi menjadi tiga bagian. Kelima bagian itu adalah:

1) Interferensi semantik perluasan (semantic expansive interference). Istilah ini dipakai apabila terjadi peminjaman konsep budaya dan juga nama unsur bahasa sumber.

2) Interferensi semantik penambahan ( semantic aditif interference). Interferensi ini terjadi apabila muncul bentuk baru berdampingan dengan bentuk lama, tetapi bentuk baru bergeser dari makna semula. Interferensi semantik penggantian (replasive semantic interference). Interferensi ini terjadi apabila muncul makna konsep baru sebagai pengganti konsep lama.

\section{Jenis- jenis Interferensi}

Interferensi dalam bidang fonologi terdiri dari interferensi fonologis pengurangan, penambahanhuruf, dan fonologis perubahan huruf.

Interferensi bidang morfologi, antara lain, terdapat dalam pembentukan kata dengan afiks. Afiks- afiks suatu bahasa digunakan untuk membentuk kata dalam bahasa lain. Umpamanya dalam bahasa Belanda dan Inggris ada sufiksisasi, maka banyak penutur bahasa Indonesia yang menggunakannya dalam dalam pembentukan kata bahasa Indonesia seperi neonisasi, turinisasi, tendanisasi, dll.

Chaer (2003: 123) mengemukakan bahwa bentuk- bentuk tersebut merupakan penyimpangandari sistematik morfologi bahasa Indonesia. Hal ini dijelaskan bahwa untuk membentuk nomina proses dalam bahasa Indonesia ada konfiks pe-an. Jadi seharusnya peneonan, perturian, penendaan, dll.

Interferensi bidang morfologi terjadei pula dari afiks bahasa daerah. Chaer ( 2003: 123) mengemukakan bahawa penggunaan bentuk- bentuk kekecilan, ketabrak, kemahalan dalam bahasa Indonesia juga termasuk kasus interferensi, serbab imbuhan yang digunakan di situ berasal dari bahasa Jawa atau Sunda dan dialek Jakarta. Bentuk yang bakau adalah terlalu kecil,tertabrak, terlalu mahal.

Interferensi dalam bidang sintaksis, pada bunyi kalimat bahasa Indonesia dari seorang bilingual Jawa-Indonesia. Bunyi kalimat tersebut “ Di sini dibangun rumah susun yang mahal sendiri.” Kalimat bahasa Indonesia ini berstrutur bahasa Jawa. Kata sendiri dalam bahasa Indonesia itu merupakan terjemahandari kata Jawa dhewe.

Interferensi dalam bidang leksikal lainnya diambil dari contoh kalimat dalam bahasa Sunda-Indonesia yang dicontohkan Chaer (2003: 263). Contoh tersebut adalah, Buku itu telah dibaca oleh saya. Kalimat tersebut adalah bentuk terinterferensi oleh bahasa Sunda, sebab dalam bahasa Sunda berbunyi eta surat geus dibaca ku kuring. Dalam bahasa Indonesia kalimatnya haruslah Surat itu sudah saya baca.

Interferensi dipandang sebagai pengacauan karena merusak sistem suatu bahasa, tetapi pada sisi lain interferensi dipandang sebagai suatu mekanisme yang paling penting dan dominan untuk mengembangkan suatu bahasa. Pda subsistem fonologi, morfologi, dan sintaksis. 


\section{Solusi untuk Mencegah Interferensi}

Interferensi adalah sebuah peristiwa yang menjadi topik masalah dan sulit untuk dihilangkan bahkan tidak bisa dihilangkan.Unsur-unsur di dalam bahasa pertama secara langsung mauoun tidak langsung akan terbawa dan akan masuk ke dalam pemakaian bahasa keduanya. Dalam proses pembelajaran berbahasa akan kelihatan seseorang yang sedang belajar berbahasa dengan bahasa keduanya. Eksistensi interferensi yang digunakan untuk mengatasi permasalahan dalam interferensi adalah

Pertama, dalam kasus pada proses diskusi yang dilakukan para siswa, peran guru sebagai fasilitator sangat dibutuhkan. Kedua, para siswa harus lebih sadar dan paham bahwa dirinya mengalami kesalahan berbahasa.oleh karena itu para siswa dituntut untuk banya belajar agar tahu akan kesalahan yang terjadi pada dirinya. Ketiga, para siswa harus mau dan mampu mengembangkan sikap berbahasa terutama berbahasa dengan baik dan benar.

Anderson (dalam Sumarsono, 2004: 363), mengemukakan sikap bahasa adalah tata keyakinan yang relatif berjangka panjang sebagian mengenai bahasa tertentu, mengenai objek bahasa yang memberikan kecenderungan pada seseorang agar bereksi dengan cara tertentu pula atau dengan cara cara yang disenangi.

\section{SIMPULAN}

Proses komunikasi merupakan kebutuhan manusia, baik komunikasi berbentuk lisan maupun tulisan, Komunikasi dan bahasa merupakan satu kesatuan yang tidak dapat dipisahkan dengan interaksi yang dilakukan terhadap lingkungannya. Hal tersebut dilakukan untuk menyampaikan gagasan, ide, pesan, dan lain sebagainya yang berkaitan dengan interaksi. Alat yang digunakan untuk berkomunikasi adalah bahasa.

Interferensi terjadi disebabkan oleh kekurangpengetahuan terhadap bahasa target, karena kedudukan lawan bicara, faktor- faktor yang menyangkut pribadi seorang penutur yang tidak menguasai bahasa dalam masyarakat tutur.

Interferensi fonologi terdiri dari interferensi fonologis pengurangn, penambahan huruf, dan perubahan huruf. Perubahannya biasa terjadi seperti penghilangan fonem pada awal, tengah, akhir, atau melalui proses penggabungan , pelepasan, penyisipan, asimilasi, dan desimilasi.

Interferensi Morfologi merupakan proses afiksasi yang terbentuk pada kata yang berasal dari bentuk dasar bahasa Indonesia+afiks bahasa daerah.

Interferensi Sintaksis terjadi apabila strutur bahasa lain (bahasa daerah) digunakan dalam pembentukan kalimat pada bahasa yang digunakan. Penyerapan unsur kalimatnya dapat berupa kata, frase, atau klausa.

Interferensi Leksikon terjadi apabila adanya pencampuran bahasa pertama yang menjadi serpihan dalam bahasa kedua, baik kata maupun frasa bahasa pertama.

Interferensi sebagai salah satu bidang garapan sosiolinguistik terjadi sebagai akibat adanya penggunaan bahasa kedua dalam masyarakat bilingual maupun multilingual. Transfer dari bahasa pertama ke bahasa kedua atau sebaliknya cenderung memberikan 
dampak yang kurang baik yang disebut interferensi. Interferensi berbahasa dapat terjadi di setiap tataran bahasa dan setiap komunitas masyarakat tutur.Interferensi juga terjadi dalam pembelajaran disebut (learning interference). Interferensi yang demikian itu disebut interferensi perlakuan (performance interference).

Berdasarkan pendapat di atas, latar belakang interferensi bahasa berkaitan erat dengan sikap bahasa. Menurut Bawa (1981:8) terdapat tiga ciri pokok perilaku atau sikap bahasa. Ketiga ciri pokok sikap bahasa itu adalah (i) language loyality, yaitu sikap loyalitas/kesetiaan terhadap bahasa; (ii) language pride, yaitu sikap kebanggaan terhadap bahasa; dan (iii) awareness of the norm, yaitu sikap sadar adanya norma bahasa. Jika wawasan terhadap ketiga ciri pokok atau sikap bahasa itu kurang sempurna dimiliki seseorang, berarti penutur bahasa itu bersikap kurang positif terhadap keberadaan bahasanya "Penggunaan unsur-unsur bahasa asing dalam wacana/kalimat bahasa Indonesia sangat berkaitan erat dengan masalah sikap bahasa.

Terjadinya interferensi adalah kerena pengaruh bahasa asing. Yang dimaksud bahasa asing dapat dilihat dari tiga sudut, yaitu wilayah asal, pemerolehan bahasa, dan fungsi sosio-kultural-politis. (1) Dari sudut asalnya dapat dirumuskan bahwa semua bahasa yang bukan berasal dari wilayah Indonesia adalah bahasa asing. (2) Dari sudut pemerolehan bahasa dapat dibedakan bahasa pertama (bahasa ibu) dan bahasa kedua (cenderung bahasa resmi/nasional), dan bahasa ketiga (bahasa asing). Di negara-negara yang penduduknya multietnis, yang menggunakan bahasa kedua yang berbeda dengan sebagian besar bahasa yang digunakan sehari- hari di dalam lingkungan keluarga, seperti di Indonesia dan Filipina, bahasa ketiga adalah bahasa asing. (3) Dari sudut sosio-kulturalpolitis, bahasa asing adalah bahasa yang tidak digunakan dalam interaksi sosial sehari-hari, tidak dipakai untuk pengantar mata pelajaran di sekolah secara nasional, dan tidak dipakai sebagai alat komunikasi politik dan pemerintah

\section{DAFTAR PUSTAKA}

Alwasilah, A. Chaedar. 1985. Beberapa Madhab dan Dikotomi Teori. Bandung: Angkasa. Chaer, Abdul dan Agustina, Leonie. 2010. Sosiolinguistik. Jakarta : PT Rineka Cipta. Jendra, I. Wayan. 1991. Dasar-dasar Sosiolinguistik. Denpasar: Ikayana.

Kreidler, Charles W. 1998. Introduction English Semantic. London: Routledge. Suwito, M. 2001. Sosiolinguistik. Surakarta: UNS Press

Tarigan, Henry Guntur. 2009. Pengajaran Kedwibahasaan. Bandung: Angkasa. 